\title{
Association Between COVID-19 and ABO Blood Groups: An Analysis on Convalescent Plasma Donors in Turkey
}

\author{
- Mustafa Yilmaz, ๑ Aziz Karaca, • Nazli Nadire Sozmen, ๑ Mustafa Nuri Guncikan, \\ ๑ Gizem Gokce Karadag, ๑ Nurettin Hafizoglu, ๑ Kerem Kinik*, ๑ Fatma Meric Yilmaz*,**
}

General Directorate of National Blood Services, Turkish Red Crescent, Ankara, Turkey

*Managing Board, Turkish Red Crescent, Ankara, Turkey

**Yıldırım Beyazıt University Faculty of Medicine, Department of Basic Medical Sciences, Ankara, Turkey

\section{Abstract}

\begin{abstract}
Aim: To investigate if there is an association between the blood groups of convalescent plasma (CP) donors and Severe acute respiratory syndrome Coronavirus-2 infection risk.

Methods: Blood groups of 30605 CP donors were compared with 1316676 Turkish Red Crescent (TRC) whole blood donors. Software data of TRC for the period between 07 April 2020 and 11 December 2020 was analyzed as a retrospective cohort study.

Results: Coronavirus disease-2019 (COVID-19) infection risks were higher in $A(46.1 \%$ vs. 41.6\%, $p=0.001), A B(8.3 \%$ vs. $7.6 \%$, $p=0.001)$, Rh (+) (89.2\% vs. 87.5\%, p=0.001), A Rh (+) (41.1\% vs. 36.6\%, p=0.001) and AB Rh (+) (7.4\% vs. 6.6\%, $p=0.001)$ groups; they were lower in O (29.8\% vs. 34.4\%, p=0.001), B (15.9\% vs. $16.4 \%, p=0.008)$, Rh (-) (10.8\% vs. 12.5\%, p=0.001), B Rh (-) (1.7\% vs. $2.0 \%, p=0.001), O$ Rh (+) (26.6\% vs. $29.9 \%, p=0.001)$ and $O$ Rh $(-)(3.2 \%$ vs. $4.5 \%, p=0.001)$ groups.
\end{abstract}

Conclusions: There might be an increased COVID-19 risk in $A, A B, R h(+)$ and $A$ Rh $(+)$ and $A B$ Rh $(+)$ groups as well as a decreased risk in $\mathrm{O}, \mathrm{B}, \mathrm{Rh}(-)$ and $\mathrm{O} \mathrm{Rh}(+), \mathrm{O} \mathrm{Rh}(-)$ and $\mathrm{B} \mathrm{Rh}(-)$ groups.

Keywords: Convalescent plasma donors, blood groups, COVID-19, SARS-CoV-2, age, gender

\section{Introduction}

Coronavirus disease-2019 (COVID-19), which was reported to have emerged in Wuhan city of Hubei province of People's Republic of China with the etiologic agent Severe acute respiratory syndrome-Coronavirus-2 (SARS-CoV-2) during last days of 2019, spread rapidly and led to a pandemic. At the time of this study, the virus has infected over 150 million people and led to the death over 3 million people in 224 countries/regions around the world (1). In Turkey, the number of cases reached around 5 million and about 41000 deaths occurred (2).

There is no definite cure for the disease yet. After the approval by U.S. Food and Drug Administration for emergency use of COVID-19 convalescent plasma (CP) for patients (3), Republic of Turkey Ministry of Health decided that COVID-19 CP could be used for the treatment of COVID-19 patients. In this context, Turkish Red Crescent (TRC) started accepting COVID-19 CP donations.

A relationship between the risk of developing SARS (also known as SARS caused by SARS-CoV-1 infection) with $A B O$ blood type and the severity of associated complications was reported (4). The recent evidence has shown that there is also a relationship between $A B O$ and $\mathrm{Rh}$ blood group systems and COVID-19 disease (5). The interest in the subject has started to increase after the publication of the study by Zhao et al. (6) which has shown for the first time that there is a higher risk of SARS-CoV-2 infection and COVID-19 disease for people with blood group $\mathrm{A}$ and a lower risk for people with blood group $\mathrm{O}$.

Address for Correspondence: Nazli Nadire Sozmen, General Directorate of National Blood Services, Turkish Red Crescent, Ankara, Turkey 
Different results in terms of the relationship between $A B O$ and Rh groups and COVID-19 disease were revealed in two studies by Goker et al. (7) and Arac et al. (8) in Turkey. We compared the ABO blood group distribution of CP donors of TRC, who had been infected with and recovered from COVID-19 disease, with the healthy, voluntary and, non-remunerated donation blood donors of TRC; in order to analyze the relationship between $A B O$ blood group system and contracting SARS-CoV-2 infection, using a larger sample group. Our aim is to investigate whether there is a significant difference between blood groups and the risk of contracting COVID-19.

\section{Methods}

\section{Study Design}

This study was approved by the Turkish Red Crescent Blood Services General Directorate Ethical Board (2021/4; 12.02.2021). Software data of TRC for the period between 07 April 2020 and 11 December 2020 was analyzed as a retrospective cohort study. In this period, a total of 30605 people have donated CP in TRC Blood Donation Centers. All these people were included in the study. Likewise all the 1316676 healthy, voluntary and, non-remunerated whole blood (WB) donors of TRC Blood Donation Centers were included as the control group in the study. Both CP and WB donations are accepted independent of the actual need for each blood groups. All the donors had given their consent before donation.

WB donors should be eligible to donate blood in accordance with the National Blood Guide (9), published by the Republic of Turkey Ministry of Health. The requirements per the COVID-19 CP Supply and Clinical Use Guide (10) published by the Republic of Turkey Ministry of Health for CP donation is as follows:

1- General requirements for being a WB donor and;

2- Positive laboratory test (nasopharynx swab polymerase chain reaction (PCR) test or SARS-CoV-2 antibodies serological test) and;

3- Fourteen days after resolution of clinical symptoms (cough, fever, dyspnea, fatigue etc.) and two negative PCR test results from nasopharyngeal swab (one of them should be performed in the last 48 hours) or;

4- If 28 days have passed after resolution of clinical symptoms, negative PCR test results are not necessary.

The repetitive donations in both groups were taken out from the data and only one blood group for one donor was analyzed. Blood groupings were performed with the Gel Centrifugation method; through Grifols (Grifols-Erytra, Spain) device and Grifols (Grifols, Spain) kits.

\section{Statistical Analysis}

For statistical analyses, frequency analysis was performed in variable groups and percentages were evaluated. Chi-squared analysis was implemented while analyzing the relationships between the groups of nominal variables. Chi-squared analysis was performed after checking the expected values in cells of $2 \times 2$ tables. The risk was estimated by contrasting the ratio of incidence in the group with the risk factor to the group without it. The results were regarded as significant if it was $p<0.05$. Analyses were made using SPSS version 25.0 (IBM Corp., Armonk, NY, USA).

\section{Results}

The average age of CP donors was (mean \pm SD) $36.1 \pm 0.19$; while it was $36.7 \pm 0.06$ for the WB donors in control group. Gender distribution of $\mathrm{CP}$ donors and WB donors was as follows; males/females (\%) 94/6; 88/12, respectively. In CP donors, the percentage of males was higher than WB donors since TRC does not accept plasma donations of any kind from females who have had any pregnancy history including miscarriages or $\mathrm{D} / \mathrm{C}$, due to the risk of transfusion-related acute lung injury in the recipient.

$A B O$ and $R h$ blood group distribution of $W B$ and $C P$ donors are as shown in Figures 1 and 2 .

When two blood donation groups were compared, $A$, $A B$ and $R h(+)$ groups were found to be more common in $C P$ group than $W B$ group $(p=0.001)$. $C P$ group had significantly lower $\mathrm{O}, \mathrm{B}$ and $\mathrm{Rh}(-)$ group rates than the WB control group $(p=0.001, p=0.008$ and $p=0.001$; respectively) (Table 1 ).

We performed detailed analyses in order to see if the significant differences of risk in certain groups persisted between genders and age groups. In this context, CP and WB donors have been categorized as young adulthood (18 to 35 years), middle-aged (36 to 55 years), and older adulthood (56 years and older) in accordance with Petry's study (11).

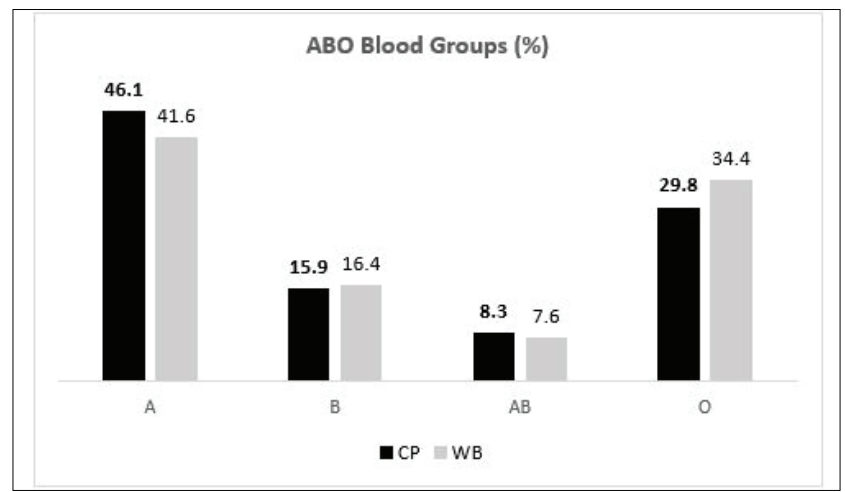

Figure 1. $A B O$ blood group distribution among $C P$ and $W B$ donors

CP: Convalescent plasma WB: Whole blood 
The significant risk difference observed in the A group between CP and WB donors has been observed in all male age groups and young adult females. The significant risk difference observed in the $\mathrm{B}$ group between $\mathrm{CP}$ and $\mathrm{WB}$ donors has not been observed in any gender and age groups. The significant risk difference observed in the $A B$ group between CP and WB donors has been observed in young and middle-aged adult males and older adult females. The significant risk difference observed in the $O$ group between CP and WB donors has been observed only in males of all age groups. The significant risk difference between Rh (+) and Rh (-) groups between CP and WB donors has been observed in young and middle-aged adult males and young adult females (Table 2 ).

$\mathrm{A} R \mathrm{Rh}(+)$ and $\mathrm{AB} \mathrm{Rh}(+)$ groups were significantly higher in $\mathrm{CP}$ group, while B Rh (-), O Rh (+) and O Rh (-) group rates were found to be significantly lower $(p=0.001)$ (Table 3$)$.

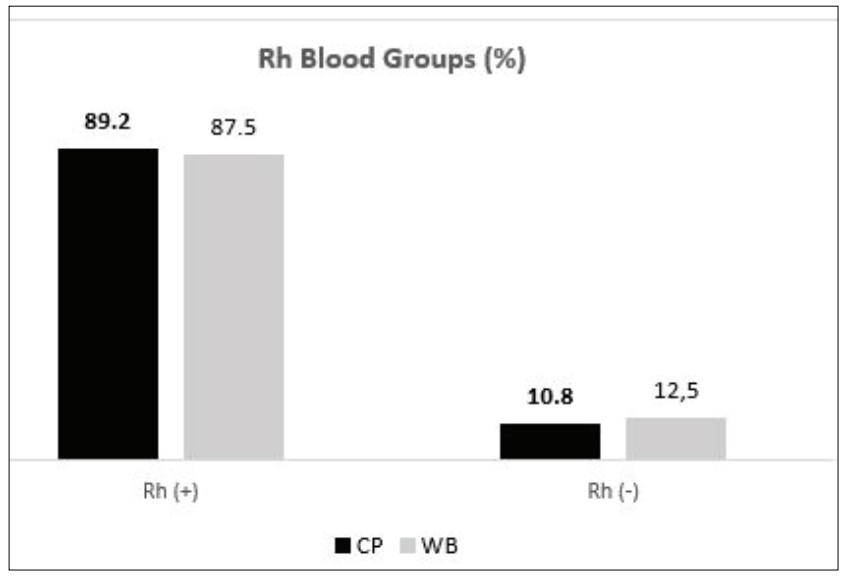

Figure 2. Rh blood group distribution among $C P$ and WB donors CP: Convalescent plasma, WB: Whole blood

\begin{tabular}{|c|c|c|c|c|}
\hline & CP n (\%) & WB n (\%) & $\mathbf{p}^{\mathrm{a}}$ & OR (95\% Cl) \\
\hline A & $14098(46.1 \%)$ & $548296(41.6 \%)$ & 0.001 & $\begin{array}{l}1.20 \\
(1.17-1.22)\end{array}$ \\
\hline B & 4853 (15.9\%) & 216204 (16.4\%) & 0.008 & $\begin{array}{l}0.96 \\
(0.93-0.99)\end{array}$ \\
\hline$A B$ & $2541(8.3 \%)$ & 99423 (7.6\%) & 0.001 & $\begin{array}{l}1.11 \\
(1.06-1.16)\end{array}$ \\
\hline 0 & $9113(29.8 \%)$ & 452753 (34.4\%) & 0.001 & $\begin{array}{l}0.81 \\
(0.79-0.83)\end{array}$ \\
\hline $\operatorname{Rh}(+)$ & $27292(89.2 \%)$ & $1151592(87.5 \%)$ & 0.001 & $\begin{array}{l}1.18 \\
(1.14-1.23)\end{array}$ \\
\hline $\operatorname{Rh}(-)$ & $3313(10.8 \%)$ & $165084(12.5 \%)$ & 0.001 & $\begin{array}{l}0.85 \\
(0.82-0.88)\end{array}$ \\
\hline \multicolumn{5}{|c|}{$\begin{array}{l}\text { a: Chi-square }\left(x^{2}\right) \text { test was used. There is a significant difference between al } \\
\text { ABO blood groups in CP donors and WB donors. The reference for each group is } \\
\text { all other } 3 \text { groups for ABO blood groups. The reference for the Rh group is the } \\
\text { other Rh group. CP: Convalescent plasma, WB: Whole blood, OR: Odds ratio, CI } \\
\text { Confidence interval }\end{array}$} \\
\hline
\end{tabular}

Regarding the significant risk differences in different combinations of $\mathrm{ABO}$ and Rh groups, we performed detailed analyses to see if these persisted between genders and age groups.

The significant risk difference observed in the A Rh (+) group between CP and WB donors has been observed in males of all age groups and young adult females. The significant risk difference observed in the B Rh (-) group between $\mathrm{CP}$ and $\mathrm{WB}$ donors in young and middle-aged adult males and young adult females. The significant risk difference observed in the $A B R h(+)$ group between $C P$ and WB donors in young and middle-aged adult males and older adult females. The significant risk difference observed in the $\mathrm{O} R \mathrm{Rh}(+)$ group between $\mathrm{CP}$ and $\mathrm{WB}$ donors only in males all of age groups. The significant risk difference observed in the O Rh (-) group between CP and WB donors has been observed in young and middle-aged adult males and middle-aged adult females (Table 4).

\section{Discussion}

In our study, we evaluated the risk association of COVID-19 infection with $A B O$ and $R h$ blood groups in $C P$ donors. There was a significantly increased risk in $A$, $\mathrm{AB}$ and $\mathrm{Rh}(+)$ groups in $\mathrm{CP}$ donors compared to the WB donors control group while a significantly decreased risk was observed in $\mathrm{O}, \mathrm{B}$ and $\mathrm{Rh}(-)$ groups. A Rh (+) and AB Rh $(+)$ groups had an increased risk while B Rh (-), O Rh (+) and O Rh (-) groups had a decreased risk for COVID-19 infection.

$A B O$ antigens expressed on tissues such as epithelium and vascular endothelial cells as well as erythrocytes in humans were associated with various diseases (12). Rh (D) phenotypes were also associated with several diseases (13-15).

Zhao et al. (6) have shown for the first time that there is a higher risk of SARS-CoV-2 infection and COVID-19 disease for people with blood group $A$ and a lower risk for people with blood group O. Although studies $(7,16-$ 24) and meta-analyses (25-27) from different continents and ethnicities verifying this relationship were published; studies which don't verify this relationship were also published (8,28-33). Goel et al. (34) attributed these different findings to different study populations, control groups, and geographical locations in addition to confounding factors such as age, comorbidities.

The higher risk of SARS-CoV-2 infection for blood group A versus blood group $O$ is hypothetically attributed to the presence of anti-A antibodies in the serum of people with O blood group which can inhibit the virus-cell adhesion process by Khalil et al. (32). This might also explain the decreased risk in $\mathrm{O}$ and $\mathrm{B}$ blood groups in our study.

On the other hand, in our study, we detected that the risk of COVID-19 infection is increased in people with 
Table 2. ABO and Rh blood group distribution in CP and WB donors by gender and age

\begin{tabular}{|c|c|c|c|c|c|c|c|}
\hline & & \multicolumn{3}{|c|}{ Male } & \multicolumn{3}{|c|}{ Female } \\
\hline & Age & $18-35$ & $36-55$ & $>55$ & $18-35$ & $36-55$ & $>55$ \\
\hline \multirow{4}{*}{ A } & CP n (\%) & $5702(45.6 \%)$ & $7141(46.9 \%)$ & $496(44.4 \%)$ & $694(43.9 \%)$ & $64(40.5 \%)$ & $1(20.0 \%)$ \\
\hline & WB n (\%) & $216608(41.8 \%)$ & $224481(41.9 \%)$ & $42229(41.2 \%)$ & $36933(40.7 \%)$ & $23762(40.7 \%)$ & $4283(39.5 \%)$ \\
\hline & $p^{a}$ & 0.001 & 0.001 & 0.031 & 0.011 & 0.97 & 0.373 \\
\hline & OR $(95 \% \mathrm{Cl})^{\mathrm{b}}$ & $1.17(1.12-1.21)$ & $1.23(1.19-1.27)$ & $1.14(1.01-1.28)$ & $1.14(1.03-1.26)$ & $0.99(0.72-1.37)$ & $0.38(0.04-3.43)$ \\
\hline \multirow{4}{*}{ B } & CP n (\%) & $1988(15.9 \%)$ & 2427 (15.9\%) & $178(15.9 \%)$ & $240(15.2 \%)$ & $20(12.7 \%)$ & $0(0 \%)$ \\
\hline & WB n (\%) & $85645(16.5 \%)$ & $87050(16.3 \%)$ & $16912(16.5 \%)$ & $14909(16.4 \%)$ & $9819(16.8 \%)$ & $1869(17.2 \%)$ \\
\hline & $\mathbf{p}^{\mathrm{a}}$ & 0.056 & 0.311 & 0.61 & 0.183 & 0.164 & 0.308 \\
\hline & OR $(95 \% \mathrm{Cl})^{\mathrm{b}}$ & $0.95(0.91-1.00)$ & $0.98(0.94-1.02)$ & $0.96(0.82-1.13)$ & $0.91(0.79-1.05)$ & $0.72(0.45-1.15)$ & - \\
\hline \multirow{4}{*}{$A B$} & CP n (\%) & 1051 (8.4\%) & $1258(8.3 \%)$ & $94(8.4 \%)$ & 125 (7.9\%) & $11(7.0 \%)$ & $2(40.0 \%)$ \\
\hline & WB n (\%) & $39341(7.6 \%)$ & $40201(7.5 \%)$ & $7573(7.4 \%)$ & $6963(7.7 \%)$ & $4503(7.7 \%)$ & $842(7.8 \%)$ \\
\hline & $p^{a}$ & 0.001 & 0.001 & 0.193 & 0.731 & 0.727 & 0.007 \\
\hline & OR $(95 \% \mathrm{Cl})^{\mathrm{b}}$ & $1.12(1.05-1.19)$ & $1.11(1.05-1.18)$ & $1.15(0.93-1.42)$ & $1.03(0.86-1.24)$ & $0.89(0.49-1.66)$ & $7.92(1.32-47.46)$ \\
\hline \multirow{4}{*}{0} & CP n (\%) & 3777 (30.2\%) & $4398(28.9 \%)$ & $350(31.3 \%)$ & $523(33.1 \%)$ & 63 (39.9\%) & $2(40.0 \%)$ \\
\hline & WB n (\%) & $176727(34.1 \%)$ & $183991(34.3 \%)$ & $35842(35.0 \%)$ & 31980 (35.2\%) & $20364(34.8 \%)$ & $3850(35.5 \%)$ \\
\hline & $\mathbf{p}^{a}$ & 0.001 & 0.001 & 0.011 & 0.074 & 0.185 & 0.834 \\
\hline & OR $(95 \% \mathrm{Cl})^{\mathrm{b}}$ & $0.84(0.80-0.87)$ & $0.78(0.75-0.81)$ & $0.85(0.75-0.96)$ & $0.91(0.82-1.01)$ & $1.24(0.90-1.71)$ & $1.21(0.20-7.25)$ \\
\hline \multirow{4}{*}{ Rh + } & CP n (\%) & $11148(89.1)$ & $13599(89.3)$ & $991(88.6)$ & $1417(89.6)$ & $132(83.5)$ & $5(100.0)$ \\
\hline & WB n (\%) & $453919(87.6 \%)$ & 468901 (87.5\%) & 89957 (87.7\%) & $78756(86.8 \%)$ & $50570(86.5 \%)$ & 9489 (87.5\%) \\
\hline & $p^{a}$ & 0.001 & 0.001 & 0.348 & 0.001 & 0.274 & 0.398 \\
\hline & OR $(95 \% \mathrm{Cl})^{b}$ & $1.16(1.09-1.22)$ & $1.19(1.13-1.26)$ & $1.09(0.91-1.32)$ & $1.31(1.12-1.54)$ & $0.79(0.52-1.21)$ & - \\
\hline \multirow{4}{*}{ Rh - } & CP n (\%) & 1370 (10.9\%) & 1625 (10.7\%) & $127(11.4 \%)$ & $165(10.4 \%)$ & $26(16.5 \%)$ & $0(0 \%)$ \\
\hline & WB n (\%) & $64402(12.4 \%)$ & $66822(12.5 \%)$ & $12599(12.3 \%)$ & $12029(13.3 \%)$ & $7878(13.5 \%)$ & $1355(12.5 \%)$ \\
\hline & $\mathbf{p}^{\mathrm{a}}$ & 0.001 & 0.001 & 0.348 & 0.001 & 0.274 & 0.398 \\
\hline & OR $(95 \% \mathrm{CI})^{\mathrm{b}}$ & $0.87(0.82-0.92)$ & $0.84(0.80-0.88)$ & $0.92(0.76-1.10)$ & $0.76(0.65-0.90)$ & $1.26(0.83-1.93)$ & - \\
\hline
\end{tabular}

Table 3. ABO-Rh type blood group distribution in CP and WB donors

\begin{tabular}{|l|l|l|l|l|}
\hline & CP $\mathbf{~ ( \% ) ~}$ & WB $\mathbf{~ ( \% ) ~}$ & $\mathbf{p}^{\mathbf{a}}$ & OR (95\% Cl) \\
\hline A Rh (+) & $12579(41.1 \%)$ & $482390(36.6 \%)$ & $\mathbf{0 . 0 0 1}$ & $1.21(1.18-1.24)$ \\
\hline A Rh (-) & $1519(4.9 \%)$ & $65906(5.0 \%)$ & 0.738 & $0.99(0.94-1.04)$ \\
\hline B Rh (+) & $4332(14.2 \%)$ & $189655(14.4 \%)$ & 0.219 & $0.98(0.95-1.01)$ \\
\hline B Rh (-) & $521(1.7 \%)$ & $26549(2.0 \%)$ & $\mathbf{0 . 0 0 1}$ & $0.84(0.77-0.92)$ \\
\hline AB $\mathbf{R h}(+)$ & $2255(7.4 \%)$ & $86506(6.6 \%)$ & $\mathbf{0 . 0 0 1}$ & $1.13(1.08-1.18)$ \\
\hline AB $\mathbf{R h}(-)$ & $286(0.9 \%)$ & $12917(1.0 \%)$ & 0.414 & $0.95(0.85-1.07)$ \\
\hline $\mathbf{0} \mathbf{R h}(+)$ & $8126(26.6 \%)$ & $393041(29.9 \%)$ & $\mathbf{0 . 0 0 1}$ & $0.85(0.83-0.87)$ \\
\hline $\mathbf{0} \mathbf{R h}(-)$ & $987(3.2 \%)$ & $59712(4.5 \%)$ & $\mathbf{0 . 0 0 1}$ & $0.70(0.66-0.75)$ \\
\hline
\end{tabular}

a: Chi-square $\left(x^{2}\right)$ test was used. There is a significant difference between all $A B O$ and Rh blood groups in CP donors and WB donors. The reference for each group is all other groups. CP: Convalescent plasma, WB: Whole blood, OR: Odds ratio, Cl: Confidence interval

$\mathrm{Rh}(+)$ while it is decreased in people with Rh (-). Several studies revealed that people with $\mathrm{Rh}(+)$ have an increased risk of COVID-19 infection $(8,30,35)$ while people with $R h$ (-) has decreased risk $(8,36)$. Contrary to our study and the literature in general, one study has suggested that Rh $(+)$ blood types are less susceptible to COVID-19 (33). Another study has found no significant difference regarding Rh blood groups (29). 
Yilmaz et al. Blood Groups and COVID-19

\begin{tabular}{|c|c|c|c|c|c|c|c|}
\hline & \multirow[b]{2}{*}{ Age } & \multicolumn{3}{|l|}{ Male } & \multicolumn{3}{|l|}{ Female } \\
\hline & & $18-35$ & $36-55$ & $>55$ & $18-35$ & $36-55$ & $>55$ \\
\hline \multirow{4}{*}{ A Rh + } & CP n (\%) & $5082(40.6 \%)$ & $6380(41.9 \%)$ & 444 (39.7\%) & $619(39.1 \%)$ & $53(33.5 \%)$ & $1(20.0 \%)$ \\
\hline & WB n (\%) & 190925 (36.8\%) & 197388 (36.9\%) & $37181(36.3 \%)$ & 32305 (35.6\%) & $20808(35.6 \%)$ & 3783 (34.9\%) \\
\hline & $\mathbf{p}^{\mathrm{a}}$ & 0.001 & 0.001 & 0.017 & 0.004 & 0.59 & 0.485 \\
\hline & OR $(95 \% \mathrm{Cl})^{\mathrm{b}}$ & $1.17(1.13-1.215)$ & $1.24(1.20-1.28)$ & $1.16(1.03-1.31)$ & $1.16(1.05-1.29)$ & $0.91(0.66-1.27)$ & $0.47(0.05-4.18)$ \\
\hline \multirow{4}{*}{ A Rh - } & CP n (\%) & $620(5.0 \%)$ & $761(5.0 \%)$ & $52(4.7 \%)$ & $75(4.7 \%)$ & $11(7.0 \%)$ & $0(0 \%)$ \\
\hline & WB n (\%) & $25683(5.0 \%)$ & $27093(5.1 \%)$ & $5048(4.9 \%)$ & $4628(5.1 \%)$ & $2954(5.1 \%)$ & $500(4.6 \%)$ \\
\hline & $p^{a}$ & 0.991 & 0.745 & 0.677 & 0.522 & 0.274 & 0.623 \\
\hline & OR $\left(95 \% \mathrm{Cl}^{\mathrm{b}}\right.$ & $1.01(0.92-1.09)$ & $0.99(0.92-1.06)$ & $0.94(0.71-1.25)$ & $0.93(0.73-1.17)$ & $1.41(0.76-2.60)$ & - \\
\hline \multirow{4}{*}{ B Rh + } & CP n (\%) & $1779(14.2 \%)$ & $2160(14.2 \%)$ & $157(14.0 \%)$ & $221(14.0 \%)$ & $15(9.5 \%)$ & $0(0 \%)$ \\
\hline & WB n (\%) & $75217(14.5 \%)$ & 76445 (14.3\%) & $14909(14.5 \%)$ & $12981(14.3 \%)$ & $8464(14.5 \%)$ & $1639(15.1 \%)$ \\
\hline & $\mathbf{p}^{\mathrm{a}}$ & 0.346 & 0.777 & 0.641 & 0.711 & 0.075 & 0.345 \\
\hline & OR $(95 \% \mathrm{Cl})^{\mathrm{b}}$ & $0.98(0.93-1.03)$ & $0.99(0.95-1.04)$ & $0.96(0.81-1.14)$ & $0.97(0.84-1.12)$ & $0.62(0.36-1.06)$ & - \\
\hline \multirow{4}{*}{ B Rh - } & CP n (\%) & $209(1.7 \%)$ & 267 (1.8\%) & $21(1.9 \%)$ & $19(1.2 \%)$ & $5(3.2 \%)$ & $0(0 \%)$ \\
\hline & WB n (\%) & $10428(2.0 \%)$ & $10605(2.0 \%)$ & $2003(2.0 \%)$ & $1928(2.1 \%)$ & $1355(2.3 \%)$ & $230(2.1 \%)$ \\
\hline & $p^{a}$ & 0.007 & 0.048 & 0.857 & 0.011 & 0.48 & 0.742 \\
\hline & OR $(95 \% \mathrm{Cl})^{\mathrm{b}}$ & $0.827(0.72-0.95)$ & $0.88(0.78-1.00)$ & $0.96(0.62-1.48)$ & $0.56(0.36-0.88)$ & $1.38(0.56-3.36)$ & - \\
\hline \multirow{4}{*}{$A B R h+$} & CP n (\%) & $936(7.5 \%)$ & $1115(7.3 \%)$ & $82(7.3 \%)$ & 109 (6.9\%) & $11(7.0 \%)$ & $2(40.0 \%)$ \\
\hline & WB n (\%) & $34318(6.6 \%)$ & $34938(6.5 \%)$ & $6629(6.5 \%)$ & $6013(6.6 \%)$ & $3888(6.7 \%)$ & $720(6.6 \%)$ \\
\hline & $p^{a}$ & 0.001 & 0.001 & 0.239 & 0.673 & 0.876 & 0.003 \\
\hline & OR $(95 \% \mathrm{CI})^{\mathrm{b}}$ & $1.14(1.07-1.22)$ & $1.13(1.07-1.21)$ & $1.15(0.91-1.44)$ & $1.04(0.86-1.27)$ & $1.05(0.57-1.94)$ & $9.37(1.56-56.19)$ \\
\hline \multirow{4}{*}{ AB Rh - } & CP n (\%) & 115 (0.9\%) & $143(0.9 \%)$ & $12(1.1 \%)$ & $16(1.0 \%)$ & $0(0 \%)$ & $0(0 \%)$ \\
\hline & WB n (\%) & $5023(1.0 \%)$ & $5263(1.0 \%)$ & 944 (0.9\%) & $950(1.1 \%)$ & $615(1.1 \%)$ & $122(1.1 \%)$ \\
\hline & $p^{a}$ & 0.569 & 0.595 & 0.595 & 0.892 & 0.195 & 0.811 \\
\hline & OR $(95 \% \mathrm{Cl})^{\mathrm{b}}$ & $0.94(0.79-1.14)$ & $0.96(0.81-1.13)$ & $1.17(0.66-2.07)$ & $0.97(0.59-1.59)$ & $0.99(0.99-0.99)$ & - \\
\hline \multirow{4}{*}{ O Rh + } & CP n (\%) & $3351(26.8 \%)$ & $3944(25.9 \%)$ & $308(27.6 \%)$ & $468(29.6 \%)$ & $53(33.5 \%)$ & $2(40.0 \%)$ \\
\hline & WB n (\%) & $153459(29.6 \%)$ & $160130(29.9 \%)$ & $31238(30.5 \%)$ & $27457(30.2 \%)$ & $17410(29.8 \%)$ & 3347 (30.9\%) \\
\hline & $p^{a}$ & 0.001 & 0.001 & 0.035 & 0.57 & 0.302 & 0.658 \\
\hline & OR $(95 \% \mathrm{Cl})^{\mathrm{b}}$ & $0.87(0.84-0.91)$ & $0.82(0.79-0.85)$ & $0.87(0.76-0.99)$ & $0.97(0.87-1.08)$ & $1.19(0.86-1.66)$ & $1.49(0.25-8.94)$ \\
\hline \multirow{4}{*}{ O Rh - } & CP n (\%) & $426(3.4 \%)$ & $454(3.0 \%)$ & $42(3.8 \%)$ & $55(3.5 \%)$ & $10(6.3 \%)$ & $0(0 \%)$ \\
\hline & WB n (\%) & $23268(4.5 \%)$ & 23861 (4.5\%) & $4604(4.5 \%)$ & $4523(5.0 \%)$ & 2954 (5.1\%) & $503(4.6 \%)$ \\
\hline & $p^{a}$ & 0.001 & 0.001 & 0.239 & 0.006 & 0.465 & 0.622 \\
\hline & OR $\left(95 \% \mathrm{Cl}^{\mathrm{b}}\right.$ & $0.75(0.68-0.83)$ & $0.66(0.60-0.73)$ & $0.83(0.61-1.13)$ & $0.69(0.52-0.90)$ & $1.27(0.67-2.41)$ & - \\
\hline
\end{tabular}

In our study, we detected an increased risk in A Rh (+) blood group with a decreased risk in the $\mathrm{O} R \mathrm{Rh}(+)$ blood group. Taha et al. (19) found similar results. Different from the literature, there was an increased risk in $A B R h(+)$ group while there were decreased risks in $\mathrm{B} R \mathrm{Rh}(-), \mathrm{O} \mathrm{Rh}$ $(+)$ and $O$ Rh (-) groups in our study. While a decreased risk was found in group $B$ and increased risk in $\mathrm{Rh}(+)$, the combination, B Rh (+), did not have either an increased or a decreased risk. The same also applied to the combinations A Rh (-) and AB Rh (-). These results implicated that the virus has a tendency to infect individuals with Rh antigen. There was a decreased risk in group $\mathrm{O}$ regardless of $\mathrm{Rh}$ groups, possibly due to the presence of anti-A antibodies.

Different from the literature, an increased risk in the $A B$ group was found in our study similar to the results of only 4 studies $(29,30,33,37)$. Zhao et al. (6) also reported an increased risk in the $A B$ group in one of three different hospitals in their study. However, a decreased risk was observed in B group in our study while an increased risk was found in the B groups in 3 studies $(30,33,37)$. 
The significant differences we found between $\mathrm{CP}$ and WB donors for different gender and age groups were not persistent through all genders and age groups. We have searched the relevant literature using the keywords; "convalescent plasma donors", "blood groups", "COVID-19", "SARS-CoV-2", "age", "gender". However, we have not identified any studies in which the risk of COVID-19 distribution in $A B O$ and Rh group combinations by gender and age were studied.

Regarding the relationship between $A B O$ blood group types and COVID-19 and the underlying molecular mechanisms, some hypotheses have been suggested $(34,38)$. Gérard et al. $(39)$ suggested the hypothesis that $O$ group patients have a decreased risk compared to all other groups, while people with both $\mathrm{O}$ and $\mathrm{B}$ blood groups have anti-A antibody in the plasma; and hence, anti-A antibody of $\mathrm{O}$ group is more protective than the anti-A antibody of B group. This hypothesis may support the findings of our study such that the strong protective anti-A antibody in O group in our study was not affected by the Rh factor and the weaker protective anti-A antibody in B group was affected by Rh factor, in terms of COVID-19 risk.

Focosi (40) also stated in his research that anti-B antibody, mainly with anti-A antibody, can also be protective against COVID-19. In fact, based on this hypothesis, he suggested to prefer using the $\mathrm{CP}$ of $\mathrm{O}$ group donors in order to be more effective in treatment. This hypothesis might explain the decreased risk in $\mathrm{O}$ and $\mathrm{B}$ groups and the increased risk in the $A B$ group in our study. On the other hand, Kotila et al. (37) expressed that the decreased risk in blood group O could be due to potent anti-B antibodies; however, this explanation does not support our finding of an increased risk in blood group $A$.

Another hypothesis by Zaidi et al. (41) stated that blood groups were determined by sugars such as $\mathrm{N}$-acetyl galactosamine, and coronaviruses in human have surface proteins that bind to these sugars. $\mathrm{N}$-acetyl galactosamine, the extra sugar on the surface of A blood group cells, could possibly be important for more pathogen exposure. This sugar is deficient in $\mathrm{O}$ blood group cells. This hypothesis might support the increased risk in the $A$ group and decreased risk in the O group in our study.

\section{Study Limitations}

One limitation of our study is that we were not able to evaluate other potential risk factors such as smoking since this is a retrospective study. For WB/CP donation we do not inquire smoking status. However, we would expect both CP and WB donors to be in similar medical status because $C P$ donors should basically meet the same medical requirements as the WB donors. By definition, $C P$ donors are a subset of WB donors who had COVID-19 infection and then recovered. Severe medical conditions such as chronic kidney failure, chronic heart failure, active malignancy or malignancy history, ischemic heart disease, severe chronic obstructive lung disease, insulin-dependent Diabetes Mellitus require permanent deferral for $\mathrm{WB} / \mathrm{CP}$ donors.

Another limitation of our study is that the study population is composed of WB/CP donors; which might decrease the representation of the country population. However, all of the patients who recovered from COVID-19 were invited by TRC for CP donation, the blood donors were from the different cities of the country with the advantage of TRC, being the responsible body for donation; and the large study and comparison group numbers increase the power of the study.

\section{Conclusion}

The first question is "Are blood groups independent risk factors for the development of COVID-19?". While there was an increased risk of infection in $A, A B$ and $R h$ $(+)$ groups, there was a decreased risk in $\mathrm{O}, \mathrm{B}$ and $\mathrm{Rh}(-)$ groups in our study. Again, there was an increased risk in $\mathrm{A} \mathrm{Rh}(+)$ and $\mathrm{AB} \mathrm{Rh}(+)$ and decreased risk in B Rh (-), O Rh $(+)$ and $O \mathrm{Rh}(-)$. The second question is the decreased risk in group $O$ related to high concentrations of circulating anti-A and anti-B antibodies of these people? Could Rh antigen be a cause of affinity for the virus and increase the risk? It appears that there is a need for further research into the underlying mechanisms.

\section{Authorship Contributions}

Concept: M.Y., A.K., N.N.S., M.N.G., N.H., K.K., F.M.Y., Design: M.Y., A.K., N.N.S., M.N.G., N.H., K.K., F.M.Y., Data Collection or Processing: N.N.S., G.G.K., Analysis or Interpretation: N.N.S., G.G.K., Literature Search: A.K., Writing: M.Y., A.K.

Conflict of Interest: No conflict of interest was declared by the authors.

Financial Disclosure: The authors declared that this study received no financial support.

\section{References}

1. https://www.who.int/emergencies/diseases/novelcoronavirus-2019 (Accessed: May, 3.2021).

2. https://covid19.saglik.gov.tr/ (In Turkish. Accessed: May, 3.2021).

3. CBER. Investigational COVID-19 Convalescent Plasma Emergency INDs. https://notifylibrary.org/sites/default/ files/Investigational\%20COVID-19\%20Convalescent $\% 20$ Plasma\%20-\%20Emergency\%20INDs\%20_\%20FDA.pdf (Accessed December 22, 2020).

4. Cheng Y, Cheng G, Chui $\mathrm{CH}$, et al. $\mathrm{ABO}$ blood group and susceptibility to severe acute respiratory syndrome. JAMA 2005;293:1450-1. 
5. Dzik S, Eliason K, Morris EB, Kaufman RM, North CM. COVID-19 and ABO blood groups. Transfusion 2020;60:18834.

6. Zhao J, Yang $Y$, Huang $H$, et al. Relationship between the ABO Blood Group and the COVID-19 Susceptibility. Clin Infect Dis 2020:1150.

7. Goker H, Aladağ Karakulak E, Demiroğlu H, et al. The effects of blood group types on the risk of COVID-19 infection and its clinical outcome. Turk J Med Sci 2020;50:679-83.

8. Arac E, Solmaz i, Akkoc H, et al. Association Between the Rh Blood Group and the Covid-19 Susceptibility. International Journal of Hematology and Oncology 2020;30:81-6.

9. https://sbu.saglik.gov.tr/Ekutuphane/Home/ GetDocument/523 (In Turkish. Accessed: May, 3.2021).

10. https://shgmkanhizmetleridb.saglik.gov.tr/Eklenti/39167/0/ covid-19-immun-plazma-rehberi-v5.pdf (In Turkish. Accessed: May, 3.2021).

11. Petry NM. A comparison of young, middle-aged, and older adult treatment-seeking pathological gamblers. Gerontologist 2002;42:92-9.

12. Ewald DR, Sumner SC. Blood type biochemistry and human disease. Wiley Interdiscip Rev Syst Biol Med 2016;8:517-35.

13. Sandler SG, Chen LN, Flegel WA. Serological weak D phenotypes: a review and guidance for interpreting the RhD blood type using the RHD genotype. $\mathrm{Br} J$ Haematol 2017;179:10-9.

14. Flegr J. Influence of latent Toxoplasma infection on human personality, physiology and morphology: pros and cons of the Toxoplasma-human model in studying the manipulation hypothesis. J Exp Biol 2013;216:127-33.

15. Kaidarova Z, Bravo MD, Kamel HT, Custer BS, Busch MP, Lanteri MC. Blood group A and D negativity are associated with symptomatic West Nile virus infection. Transfusion 2016;56:1699-706.

16. Ellinghaus D, Degenhardt F, Bujanda L, et al. Genomewide Association Study of Severe Covid-19 with Respiratory Failure. N Engl J Med 2020;383:1522-34.

17. Li J, Wang $X$, Chen J, Cai Y, Deng A, Yang M. Association between $\mathrm{ABO}$ blood groups and risk of SARS-CoV-2 pneumonia. Br J Haematol 2020;190:24-7.

18. Gallian P, Pastorino B, Morel P, Chiaroni J, Ninove L, de Lamballerie $X$. Lower prevalence of antibodies neutralizing SARS-CoV-2 in group O French blood donors. Antiviral Res 2020;181:104880.

19. Taha SAH, Osman MEM, Abdoelkarim EAA, et al. Individuals with a Rh-positive but not Rh-negative blood group are more vulnerable to SARS-CoV-2 infection: demographics and trend study on COVID-19 cases in Sudan. New Microbes New Infect 2020;38:100763.
20. Obayes AL-Khikani F. The role of blood group in COVID-19 Infection: More information is needed. Journal of Nature and Science of Medicine 2020;3:225-6.

21. Wu Y, Feng Z, Li P, Yu Q. Relationship between ABO blood group distribution and clinical characteristics in patients with COVID-19. Clin Chim Acta 2020;509:220-3. ,

22. Muñiz-Diaz E, Llopis J, Parra R, et al. Relationship between the $A B O$ blood group and COVID-19 susceptibility, severity and mortality in two cohorts of patients. Blood Transfus 2021; 19:54-63.

23. Barnkob MB, Pottegård $A$, Støvring $H$, et al. Reduced prevalence of SARS-CoV-2 infection in $\mathrm{ABO}$ blood group $\mathrm{O}$. Blood Adv 2020;4:4990-3.

24. 23andMe finds evidence that blood type plays a role in COVID19.;Available online: https://blog.23andme.com/23andmeresearch/blood-type-and-covid-19/ (accessed: 17 December 2020).

25. Wu BB, Gu DZ, Yu JN, Yang J, Shen WQ. Association between $A B O$ blood groups and COVID-19 infection, severity and demise: A systematic review and meta-analysis. Infect Genet Evol 2020;84:104485.

26. Golinelli D, Boetto E, Maietti E, Fantini MP. The association between $A B O$ blood group and SARS-CoV-2 infection: A meta-analysis. PLoS One 2020;15:0239508.

27. Pourali F, Afshari M, Alizadeh-Navaei R, Javidnia J, Moosazadeh M, Hessami A. Relationship between blood group and risk of infection and death in COVID-19: a live meta-analysis. New Microbes New Infect 2020;37:100743.

28. Flegel WA. COVID-19: risk of infection is high, independently of ABO blood group. Haematologica 2020;105:2706-8.

29. Abdollahi A, Mahmoudi-Aliabadi M, Mehrtash $V$, Jafarzadeh B, Salehi M. The Novel Coronavirus SARS-CoV-2 Vulnerability Association with $\mathrm{ABO} / \mathrm{Rh}$ Blood Types. Iran J Pathol 2020;15:156-60.

30. Latz CA, DeCarlo C, Boitano L, et al. Blood type and outcomes in patients with COVID-19. Ann Hematol 2020;99:2113-8.

31. Padhi S, Suvankar S, Dash D, et al. ABO blood group system is associated with COVID-19 mortality: An epidemiological investigation in the Indian population. Transfus Clin Biol 2020;27:253-8.

32. Khalil A, Feghali R, Hassoun M. The Lebanese COVID-19 Cohort; A Challenge for the ABO Blood Group System. Front Med (Lausanne) 2020;7:585341.

33. Rahim F, Amin S, Bahadur S, Noor M, Mahmood A, Gul H. ABO / Rh-D Blood types and susceptibility to Corona Virus Disease-19 in Peshawar, Pakistan. Pak J Med Sci 2021;37:4-8.

34. Goel R, Bloch EM, Pirenne F, et al. ABO blood group and COVID-19: a review on behalf of the ISBT COVID-19 working group. Vox Sang 2021:10.1111/vox.13076.

35. Zietz M, Zucker J, Tatonetti NP. Associations between blood type and COVID-19 infection, intubation, and death. Nat Commun 2020;11:5761. 
36. Ray JG, Schull MJ, Vermeulen MJ, Park AL. Association Between $\mathrm{ABO}$ and Rh Blood Groups and SARS-CoV-2 Infection or Severe COVID-19 Illness: A Population-Based Cohort Study. Ann Intern Med 2021;174:308-15.

37. Kotila TR, Alonge TO, Fowotade A, Famuyiwa OI, Akinbile AS. Association of the ABO blood group with SARS-CoV-2 infection in a community with low infection rate. Vox Sang 2021:10.1111/vox.13077

38. Zhang Y, Garner R, Salehi S, La Rocca M, Duncan D. Association between $A B O$ blood types and coronavirus disease 2019 (COVID-19), genetic associations, and underlying molecular mechanisms: a literature review of 23 studies. Ann Hematol 2021;100:1123-32.

39. Gérard C, Maggipinto G, Minon JM. COVID-19 and ABO blood group: another viewpoint. Br J Haematol 2020;190:934.

40. Focosi D. Anti-A isohaemagglutinin titres and SARS-CoV-2 neutralization: implications for children and convalescent plasma selection. Br J Haematol 2020;190:148-50.

41. Zaidi FZ, Zaidi ARZ, Abdullah SM, Zaidi SZA. COVID-19 and the $A B O$ blood group connection. Transfus Apher Sci 2020;59:102838. 